\title{
Factors influencing yield loss due to diseases in black tiger shrimp (Penaeus Monodon Fabricius, 1798) culture in Soc Trang province
}

\author{
Nhan T. Thanh \\ Faculty of Agriculture, Soc Trang Community College, Soc Trang, Vietnam
}

\begin{abstract}
ARTICLE INFO
Research Paper

Received: February 27, 2018

Revised: August 25, 2018

Accepted: October 18, 2018

Keywords

Black tiger shrimp

Shrimp diseases

Shrimp yield loss

Soc Trang

Corresponding author

Trinh Thanh Nhan

Email: ttnhan@stcc.edu.vn

ABSTRACT

This study aimed to determine the influencing factors on the yield loss due to diseases in black tiger shrimp (Penaeus monodon Fabricius, 1798) cultured in Soc Trang province. Data for the study were collected by interviewing 334 households farming black tiger shrimp in Soc Trang province in 2017. Descriptive statistical analysis was employed to evaluate the current situation of yield, disease and yield loss due to diseases in black tiger shrimp culture of households. Multiple linear regression analysis was used to determine the factors in influencing the yield loss of black tiger shrimp due to diseases. The results showed that the average black tiger shrimp yield fluctuated from 0.54 to 3.28 tons/ha/crop. The household percentage affected by black tiger shrimp diseases was from $33.3 \%$ to $90.8 \%$. The percentage of yield loss due to diseases was between 34.6 and $74.2 \%$. The influencing factors (variables) on the yield loss due to diseases included: being a member of black tiger shrimp culturing cooperative; application of trained techniques for shrimp culture and employment of tested post larva (negative correlation with the yield loss in all culture models: reformed extensive culture, semi-intensive culture and intensive culture). For semi-intensive culture and intensive culture, the yield loss due to diseases way negatively correlated with farmer's education degree, employment of accumulation pond and the total pond area for shrimp culture of household whereas farmer's age positively correlated with farmer's age.

Cited as: Trinh, N. T. (2019). Factors influencing yield loss due to diseases in black tiger shrimp (Penaeus Monodon Fabricius, 1798) culture in Soc Trang province. The Journal of Agriculture and Development 18(1), 72-79.
\end{abstract}




\title{
Yếu tố ảnh hưởng đến thiệt hại do bệnh trong nuôi Tôm Sú (Penaeus monodon Fabricius, 1798) tại tỉnh Sóc Trăng
}

\author{
Trịnh Thanh Nhân \\ Khoa Nông Nghiệp, Trường Cao Đẳng Cộng Đồng Sóc Trăng, Sóc Trăng
}

\section{THÔNG TIN BÀI BÁO \\ Bài báo khoa học \\ Ngày nhận: 27/02/2018 \\ Ngày chỉnh sửa: 25/08/2018 \\ Ngày chấp nhận: 18/10/2018}

\section{Từ khóa}

Bệnh hại trên tôm sú

Sóc Trăng

Thiệt hại năng suất

Tôm sú

Tác giả liên hệ

Trịnh Thanh Nhân

Email: ttnhan@stcc.edu.vn

\section{TÓM TẮT}

Nghiên cứu được thực hiện nhằm xác định các yếu tố ảnh hưởng đến thiệt hại do bệnh trong nuôi tôm sú trên địa bàn tỉnh Sóc Trăng. Dữ liệu được thu thập thông qua khảo sát 334 hộ nuôi tôm trên địa bàn tỉnh Sóc Trăng năm 2017. Thống kê mô tả được sử dụng để đánh giá thực trạng về năng suất, bệnh và thiệt hại trong nuôi tôm sú của nông hộ. Phân tích hồi quy tuyến tính bội được sử dụng để xác định các yếu tố ảnh hưởng đến thiệt hại do bệnh trong nuôi tôm sú. Kết quả phân tích cho thấy rằng năng suất tôm sú nuôi trung bình đạt từ 0,54 đến 3,28 tấn/ha/vụ. Tỷ lệ hộ nuôi tôm sú gặp bệnh tôm trong các mô hình nuôi từ 33,3\% đến $90,8 \%$. Tỷ lệ thiệt hại do bệnh từ 34,6\% đến 74,2\%. Các yếu tố ảnh hưởng đến thiệt hại về năng suất do bệnh là tham gia tổ hợp tác/hợp tác xã nuôi tôm sú, áp dụng kỹ thuật được tập huấn và sử dụng con giống được xét nghiệm (tương quan nghịch trong cả 03 mô hình nuôi quảng canh cải tiến, bán thâm canh và thâm canh). Đối với nuôi bán thâm canh và thâm canh, trình độ học vấn của nông hộ, sử dụng ao lắng, tổng diện tích đất nuôi tôm, áp dụng luân canh có mối tương quan nghịch và độ tuổi của nông hộ có mối tương quan thuận với tỷ lệ thiệt hại về năng suất do bệnh.

\section{1. Đặt Vấn Đề}

Sóc Trăng là một tỉnh ven biển thuộc vùng đồng bằng sông Cửu Long và hoạt động nuôi trồng thủy sản nước lợ là ngành kinh tế chủ lực của tỉnh (Nguyen \& Nguyen, 2010). Kim ngạch xuất khẩu tôm năm 2016 của tỉnh đạt 630 triệu USD, đây là một trong những tỉnh có kim ngạch xuất khẩu tôm lớn nhất cả nước (DF, 2016). Trong đó, tôm sú là một trong hai đối tượng nuôi chủ lực của ngành nuôi tôm nước lợ của tỉnh, trong 53.500 ha diện tích mặt nước nuôi tôm nước lợ năm 2016, diện tích nuôi tôm sú chiếm 34,2\% (STDARD, 2016). Trong những năm qua, mức độ thâm canh trong nuôi tôm nước lợ của tỉnh không ngừng tăng lên. Năm 2006, diện tích nuôi tôm bán thâm canh và thâm canh của tỉnh là 22.527 ha (STDA, 2007) và con số này đã tăng lên đáng kể, đạt 38.128 ha vào năm 2016 (STDARD, 2016). Xu hướng này đã chuyển dịch đúng hướng theo quy hoạch phát triển nghề nuôi tôm nước lợ của tỉnh là tăng dần mức độ thâm canh trong nuôi tôm nước lợ. Theo quy hoạch, đến năm 2030 sản lượng tôm nước lợ trong tăng lên $22,1 \%$ so với năm 2020, trong khi diện tích chỉ tăng 2,19\% (PCSTP, 2014). Điều này đồng nghĩa với việc cần nâng cao mức độ thâm canh và giảm thiệt hại trong nuôi tôm nước lợ.

Tuy nhiên, để nâng cao mức độ thâm canh cần phải chú ý đến vấn đề rủi ro trong sản xuất với diều kiện về tài chính và kỹ thuật của nông dân khi mà ngành nuôi tôm nước lợ của tỉnh đang đối mặt với nhiều thách thức từ biến đổi khí hậu và cạnh tranh về thị trường gây thiệt hại không nhỏ cho người nuôi tôm. Trong nuôi tôm nước lợ, trong đó có tôm sú, thiệt hại do bệnh là vấn đề cần được quan tâm hàng đầu bởi vì nó là một trong những nhân tố quyết định đến sự thành công của mùa vụ nuôi. Theo kết quả khảo sát của SCAP năm 2015, những rủi ro mà ngành nuôi tôm nước lợ tỉnh Sóc Trăng gặp phải đó là: rủi ro về giảm giá nhanh là khoảng $66 \%$ (tỷ lệ hộ gặp phải giảm giá nhanh), rủi ro về giá vật tư tăng nhanh khoảng $27 \%$, rủi ro do bị ép 
giá khoảng $12 \%$, rủi ro do tôm chết nhiều vì bệnh khoảng $73 \%$, rủi ro do tôm chậm lớn khoảng $22 \%$, rủi ro do tôm giống kém chất lượng khoảng $26 \%$ và rủi ro do nguồn nước ô nhiễm khoảng $18 \%$. Trong thời gian qua, đã có khá nhiều nghiên cứu khảo sát về phân tích các khía cạnh tài chính và kỹ thuật trong nuôi tôm sú được thực hiện. Các nghiên cứu này chủ yếu tập trung khía cạnh các yếu tố kỹ thuật trực tiếp ảnh hưởng đến năng suất tôm sú nuôi bao gồm chất lượng tôm giống và bệnh tôm (Nguyen \& Nguyen, 2009), thức ăn, mật độ, kinh nghiệm của nông hộ, cỡ giống và số lần thay nước (Le \& ctv., 2014). Các yếu tố ảnh hưởng đến lợi nhuận bao gồm các khoản chi phí đầu vào như thuốc, giống, cải tạo ao, máy móc và chi phí khác (Pham \& Dang, 2015). Hay chỉ tập trung phân tích năng suất, chi phí và lợi nhuận tôm sú nuôi (Nguyen \& ctv., 2010; Le \& ctv., 2012; Pham \& Dang, 2015). Trong khi đó, chưa có kết quả nghiên cứu khảo sát nào về yếu tố ảnh hưởng đến thiệt hại do bệnh được công bố. Do đó, việc xác định được các yếu tố ảnh hưởng dến thiệt hại do bệnh trong nuôi tôm nước lợ nói chung và nuôi tôm sú nói riêng là một trong những điều cần thiết. Kết quả nghiên cứu sẽ là một trong những cơ sở quan trọng trong việc tìm ra những giải pháp hữu hiệu trong quản lí và hạn chế thiệt hại do bệnh trong nuôi tôm sú.

\section{Vật Liệu và Phương Pháp Nghiên Cứu}

\subsection{Thu thập số liệu}

Số liệu cho nghiên cứu được thu thập thông qua phỏng vấn trực tiếp (với bảng câu hỏi) 334 hộ nông dân nuôi tôm sú trên địa bàn hai huyện Mỹ Xuyên và Trần Đề của tỉnh Sóc Trăng. Theo số liệu thống kê của Sở Nông nghiệp và Phát triển nông thôn tỉnh Sóc Trăng năm 2016, Mỹ Xuyên và Trần Đề là vùng nuôi tôm sú chủ lực của tỉnh với sản lượng trung bình chiếm $68 \%$ sản lượng toàn tỉnh. Mẫu được chọn bằng phương pháp ngẫu nhiên và số lượng được tính dựa trên số hộ nuôi tôm trong mỗi huyện ( $2 \%$ số hộ nuôi tôm sú trên địa bàn). Theo đó, có 241 hộ tại Mỹ Xuyên và 93 hộ tại Trần Đề được chọn (39 hộ nuôi quảng canh cải tiến, 116 hộ nuôi bán thâm canh và 179 hộ nuôi thâm canh).

Thời gian tiến hành thu thập thông tin vào tháng 12 năm 2017 và nông dân được yêu cầu cung cấp thông tin trong vụ nuôi tôm gần nhất của năm 2017.

\subsection{Phân tích số liệu}

Thống kê mô tả: nghiên cứu sử dụng thống kê mô tả với các chỉ tiêu số trung bình, tỷ lệ, tần suất, số cao nhất, thấp nhất; sử dụng bảng để mô tả các chỉ tiêu về năng suất, bệnh hại, tỷ lệ thiệt hại,...

Phân tích hồi quy tuyến tính bội: Mô hình hồi quy tuyến tính bội được sử dụng để xác định các yếu tố ảnh hưởng đến tỷ lệ thiệt hại năng suất do bệnh hại. Dựa vào kết quả phân tích thống kê mô tả và tham khảo một số nghiên cứu trước đây để chọn biến độc lập cho mô hình hồi quy. Các biến độc lập được kiểm định sự tự tương quan và đa cộng tuyến trước khi quyết định chọn biến trong mô hình hồi quy. Mức độ phù hợp của mô hình được kiểm định ở mức ý nghĩa $5 \%$. Kiểm định hệ số Durbin-Watson để kiểm tra sự tự tương quan (càng gần giá trị 2 càng tốt) và độ phóng đại (VIF) để kiểm tra hiện tượng đa cộng tuyến của các biến trong mô hình, chọn VIF $<10$ (Hoang \& Chu, 2008). Phương trình hồi quy tuyến tính bội có dạng:

$\mathrm{Y}=\mathrm{a}+\mathrm{b}_{1} \mathrm{X}_{1}+\mathrm{b}_{2} \mathrm{X}_{3}+\mathrm{b}_{3} \mathrm{X}_{3}+\ldots+\mathrm{b}_{\mathrm{n}} \mathrm{X}_{\mathrm{n}}+\varphi$

Trong đó:

Y: Biến phụ thuộc tỷ lệ thiệt hại về năng suất do bệnh.

$\mathrm{a}$ : hằng số.

$b_{1}, \ldots, b_{n}$ : Các hệ số hồi quy.

$\varphi$ : Sai số.

$\mathrm{X}_{1}, \ldots, \mathrm{X}_{\mathrm{n}}$ : Biến độc lập.

Biến phụ thuộc: Tỷ lệ thiệt hại năng suất do bệnh: $\mathrm{L}(\%)=\left(\mathrm{P}_{0}-\mathrm{P}_{0}\right) \times \mathrm{P}_{0}^{-1} \times 100$.

với:

L(\%): Tỷ lệ thiệt hại năng suất do bệnh (chọn những hộ nuôi có bệnh xuất hiện).

$\mathrm{P}_{0}$ : Năng suất bình quân của hộ không có bệnh tương ứng với mật độ tôm nuôi.

$\mathrm{P}_{1}$ : Năng suất tôm nuôi thực tế của hộ nuôi có bệnh xuất hiện.

Diễn giải các biến độc lập trong mô hình tuyến tính bội được trình bày trong Bảng 1 .

\section{Kết Quả và Thảo Luận}

3.1. Đặc điểm chung về năng suất, bệnh hại và thiệt hại năng suất tôm sú nuôi do bệnh hại

Năng suất: năng suất tôm nuôi của nông hộ trong đợt khảo sát của nghiên cứu này khá thấp, 
Bảng 1. Diễn giải các biến độc lập trong mô hình tuyến tính bội

\begin{tabular}{|c|c|c|c|}
\hline Biến độc lập & Diễn giải & $\overline{\text { Đơn vị tính }}$ & Kỳ vọng \\
\hline $\mathrm{X}_{1}$ : Trình độ học vấn & Số năm đi học của chủ hộ & Năm & - \\
\hline $\mathrm{X}_{2}$ : Tuổi & Số tuổi của chủ hộ & Tuổi & - \\
\hline $\mathrm{X}_{3}$ : Kinh nghiệm & Số năm đã nuôi tôm & Năm & + \\
\hline $\mathrm{X}_{4}$ : Tham gia hợp tác & $\begin{array}{l}\text { Hộ nuôi tôm là thành viên của tổ } \\
\text { hợp tác hoặc hợp tác xã nuôi tôm }\end{array}$ & 0: không; 1: có & - \\
\hline $\mathrm{X}_{5}$ : Có luân canh & $\begin{array}{l}\text { Biến nhị phân: có luân canh trên } \\
\text { diện tích đất nuôi tôm trong năm } \\
\text { hay không (Luân canh với đối tượng } \\
\text { khác: lúa, cá, tôm thẻ) }\end{array}$ & 0: không; 1: có & - \\
\hline $\mathrm{X}_{6}$ : Có ao lắng & $\begin{array}{l}\text { Biến nhị phân: có sử dụng ao lắng } \\
\text { trước khi cho nước vào ao nuôi tôm } \\
\text { sú hay không }\end{array}$ & 0: không; 1: có & - \\
\hline $\begin{array}{l}\mathrm{X}_{7} \text { : Tổng diện tích nuôi của } \\
\text { chủ hộ }\end{array}$ & Tổng diện tích ao nuôi tôm của hộ & ha & - \\
\hline $\begin{array}{l}\mathrm{X}_{8} \text { : Áp dụng kỹ thuật được } \\
\text { tập huấn }\end{array}$ & $\begin{array}{l}\text { Biến nhị phân: có áp dụng các kỹ } \\
\text { thuật nuôi tôm đã được tập huấn } \\
\text { vào mô hình nuôi hay không }\end{array}$ & 0: không; 1: có & - \\
\hline $\mathrm{X}_{9}$ : Sử dụng giống xét nghiệm & $\begin{array}{l}\text { Biến nhị phân: có sử dụng tôm giống } \\
\text { đã được xét nghiệm hay không }\end{array}$ & 0: không; 1: có & - \\
\hline
\end{tabular}

với năng suất trung bình trong các mô hình nuôi quảng canh cải tiến, bán thâm canh và thâm canh lần lượt là 0,$66 ; 1,15$ và 1,26 tấn/ha/vụ. Năng suất này thấp hơn kết quả khảo sát trước đây của Nguyen \& Nguyen (2010), trên địa bàn tỉnh Sóc Trăng với năng suất bình quân cho mô hình nuôi quảng canh cải tiến là 1,5 tấn/ha/vụ, mô hình bán thâm canh là 2,74 tấn/ha/vụ và mô hình thâm canh là 4,66 tấn/ha/vụ. Điều này có thể cho thấy rằng năng suất nuôi tôm sú của nông hộ đang có xu hướng giảm dần, hoạt động nuôi tôm sú trên địa bàn khảo sát gần đây đang gặp tình trạng thiệt hại về năng suất khá lớn. Trong đó, bệnh làm thiệt hại về năng suất rất lớn khi kết quả khảo sát cho thấy năng suất trung bình khi có bệnh tôm xuất hiện trong các mô hình nuôi quảng canh cải tiến, bán thâm canh và thâm canh lần lượt là 0,$54 ; 0,80$ và 1,01 tấn/ha/vụ; trong khi đó, nếu không có bệnh xuất hiện, năng suất tôm sú nuôi cao hơn rất nhiều với năng suất bình quân lần lượt là 0,$86 ; 1,98$ và 3,28 tấn/ha/vụ (Bảng 2 ).

Tỷ lệ xuất hiện dịch bệnh: sự xuất hiện của bệnh trong quá trình nuôi tôm cũng tăng dần theo mức độ thâm canh. Theo kết quả khảo sát, tỷ lệ bệnh xuất hiện trong mô hình nuôi quảng canh cải tiến là $33,3 \%$ số hộ nuôi, $67,8 \%$ và $90,8 \%$ cho mô hình nuôi bán thâm canh và thâm canh. Mức độ tác động của bệnh hại rất nghiêm trọng khi có đến $47,0 \%$ hộ nuôi tôm bán thâm canh và $88,0 \%$ hộ nuôi tôm thâm canh phải thu hoạch sớm do bệnh. Theo kết quả khảo sát, tần suất xuất hiện các bệnh trong quá trình nuôi cũng tăng theo mức độ thâm canh. Theo đó, có 5,30\% hộ nuôi tôm trong mô hình quảng canh cải tiến xuất hiện từ 02 bệnh trở lên, 6,70\% hộ nuôi trong mô hình bán thâm canh xuất hiện từ 02 bệnh trở lên và $12,2 \%$ hộ nuôi trong mô hình thâm canh xuất hiện từ 02 bệnh trở lên. Các bệnh chính xuất hiện trong đợt khảo sát là bệnh chết sớm (EMS) xuất hiện ở $43,2 \%$ số hộ nuôi, bệnh đốm trắng $7,7 \%$, bệnh gan tụy $23,3 \%$, bệnh còi $6,2 \%$ và bệnh mềm vỏ $6,2 \%$. Trong đó, tác hại của bệnh chết sớm và đốm trắng là lớn nhất khi có đến $91 \%$ hộ phải thu hoạch sớm khi xuất hiện bệnh EMS và $98,9 \%$ phải thu hoạch khi xuất hiện đốm trắng.

Kích cỡ tôm thu hoạch: kết quả khảo sát cho thấy mức độ thâm canh càng cao, kích cỡ tôm thu hoạch càng nhỏ. Kích cỡ tôm sú thu hoạch trong các mô hình quảng canh cải tiến, bán thâm canh và thâm canh lần lượt là $40,2 \mathrm{~g} / \mathrm{con}, 21,6$ $\mathrm{g} /$ con và $15,2 \mathrm{~g} / \mathrm{con}$. Kích cỡ tôm thu hoạch trong mô hình quảng canh cải tiến của nghiên cứu này cao hơn nhưng trong mô hình bán thâm canh và thâm canh thì thấp hơn so với kết quả khảo sát của Nguyen \& Nguyen (2010), với từ 30,6 đến $31,1 \mathrm{~g} / \mathrm{con}$. Tuy nhiên, trên thực tế, kích cỡ tôm thu hoạch từ 15,2 đến $21,6 \mathrm{~g} / \mathrm{con}$ trong đợt khảo 
Bảng 2. Thông tin chung về năng suất, bệnh hại và tỷ lệ thiệt hại về năng suất tôm sú nuôi theo các mô hình

\begin{tabular}{lccc}
\hline Diễn giải & Quảng canh cải tiến & Bán thâm canh & Thâm canh \\
\hline Mật độ nuôi $\left(\mathrm{con} / \mathrm{m}^{2}\right)$ & $4,57 \pm 2,42$ & $15,04 \pm 4,51$ & $33,08 \pm 1,48$ \\
Năng suất không có bệnh (tấn/ha/vụ) & $0,86 \pm 0,43$ & $1,98 \pm 0,79$ & $3,28 \pm 1,79$ \\
Năng suất khi có bệnh (tấn/ha/vụ) & $0,54 \pm 0,41$ & $0,80 \pm 0,86$ & $1,01 \pm 0,91$ \\
Tỷ lệ hộ có xuất hiện bệnh hại & 33,3 & 67,8 & 90,8 \\
Có 01 bệnh (\%) & 28,0 & 61,1 & 79,1 \\
Có 02 bệnh (\%) & 5,30 & 6,70 & 11,7 \\
Có 03 bệnh (\%) & 0,00 & 0,00 & 0,50 \\
Tỷ lệ hộ phải thu hoạch do bệnh (\%) & 10,0 & 47,0 & 88,0 \\
Tỷ lệ sông của tôm khi có bệnh (\%) & $62,4 \pm 39,4$ & $37,6 \pm 23,1$ & $16,5 \pm 12,5$ \\
Tỷ lệ sống của tôm không có bệnh $(\%)$ & $40,7 \pm 29,5$ & $20,8 \pm 21,3$ & $5,2 \pm 15,1$ \\
Kích cỡ thu hoạch của tôm (g/con) & $40,2 \pm 17,5$ & $21,6 \pm 11,6$ & $15,2 \pm 7,1$ \\
Tỷ lệ thiệt hại về năng suất do bệnh $(\%)$ & $34,6 \pm 33,5$ & $61,9 \pm 29,7$ & $74,2 \pm 19,4$ \\
\hline
\end{tabular}

sát này không phải là kích thước thu hoạch mà người nuôi tôm sú mong muốn. Phần lớn là nông dân phải thu hoạch sớm do gặp sự cố trong quá trình nuôi.

Tỷ lệ thiệt hại về năng suất do bệnh: kết quả khảo sát cho thấy mức độ thâm canh càng cao thì tỷ lệ thiệt hại về năng suất do bệnh càng cao.

\subsection{Yếu tố ảnh hưởng đến thiệt hại về năng suất tôm sú nuôi do bệnh hại}

Mô hình quảng canh cải tiến: kết quả phân tích từ mô hình hồi quy tuyến tính bội cho thấy rằng có 03 yếu tố ảnh hưởng đến tỷ lệ thiệt hại về năng suất tôm sú nuôi trong mô hình quảng canh cải tiến là tham gia tổ hợp tác/hợp tác xã nuôi tôm sú, áp dụng kỹ thuật được tập huấn và sử dụng con giống xét nghiệm. Hệ số tương quan $\mathrm{R}=0,634$ cho thấy các biến độc lập và phụ thuộc có mối tương quan khá chặt chẽ. Hệ số xác định của mô hình $R^{2}=0,402$ cho thấy các yếu tố trên ảnh hưởng 40,2\% thiệt hại về năng suất tôm nuôi. Kiểm định Durbin-Watson = 2,19 nên sự tự tương quan giữa các biến độc lập không đáng kể. Độ phóng đại $<2$ nên không có hiện tượng đa cộng tuyến trong mô hình. Mức ý nghĩa Sig. $=0,000<0,05$ cho thấy mô hình hồi quy đưa ra là phù hợp (Bảng 3$)$.

Mô hình bán thâm canh: kết quả phân tích hồi quy tuyến tính bội cho thâyy rằng có 08 yếu tố ảnh hưởng đến tỷ lệ thiệt hại về năng suất tôm sú nuôi đó là trình độ học vấn, tuổi, tham gia tổ hợp tác/hợp tác xã nuôi tôm sú, có luân canh, có sử dụng ao lắng, tổng diện tích ao của chủ hộ, áp dụng kỹ thuật được tập huấn và sử dụng con giống xét nghiệm. Hệ số tương quan $\mathrm{R}=0,642$ cho thấy các biến độc lập và phụ thuộc có mối tương quan khá chặt chẽ. Hệ số xác định của mô hình $\mathrm{R}^{2}=0,412$ cho thấy các yếu tố trên ảnh hưởng 41,2\% thiệt hại về năng suất tôm nuôi.

Mô hình nuôi thâm canh: Kết quả phân tích mô hình hồi quy tuyến tính bội trong mô hình thâm canh khá giống với mô hình nuôi bán thâm canh. Có 08 yếu tố ảnh hưởng đến tỷ lệ thiệt hại về năng suất tôm sú nuôi đó là trình độ học vấn, tuổi, tham gia tổ hợp tác/hợp tác xã nuôi tôm sú, có luân canh, có sử dụng ao lắng, tổng diện tích ao của chủ hộ, áp dụng kỹ thuật được tập huấn và sử dụng con giống xét nghiệm. Hệ số tương quan $\mathrm{R}=0,661$, hệ số xác định của mô hình $\mathrm{R}^{2}$ = 0,437 cho thấy các yếu tố trên ảnh hưởng 43,7\% thiệt hại về năng suất tôm nuôi.

Từ kết quả phân tích các mô hình hồi quy tuyến tính bội cho thấy rằng trong mô hình nuôi quảng canh cải tiến, các yếu tố trình độ học vấn, độ tuổi, kinh nghiệm, luân canh và tổng diện tích ao nuôi của nông hộ không ảnh hưởng đến tỷ lệ thiệt hại do bệnh trong quá trình nuôi tôm sú của nông dân. Trong khi đó, các yếu tố này có ảnh hưởng đến tỷ lệ thiệt hại do bệnh trong mô hình nuôi bán thâm canh và thâm canh (ngoại trình yếu tố kinh nghiệm, không có ý nghĩa thống kê).

Trình độ học vấn: nông hộ có trình độ học vấn cao có thể sẽ có thuận lợi hơn trong quá trình tiếp thu kiến thức về nuôi tôm tốt hơn, từ đó giúp họ có những biện pháp phòng và giảm thiệt hại cho tôm sú nuôi, đặc biệt là mô hình nuôi có mức độ thâm canh cao.

Độ tuổi có thể cũng là một trong những rào cản trong quá trình tiếp thu kiến thức mới nên 





dẫn đến thiệt hại do bệnh trong tôm sú nuôi cao (tương quan thuận với tỷ lệ thiệt hại về năng suất do bệnh). Lợi ích của luân canh là giúp cải tạo môi trường ao nuôi và cắt giảm mầm bệnh (Tran \& Nguyen, 2009) nên việc áp dụng luân canh trong mô hình nuôi bán thâm canh và thâm canh giúp giảm thiệt hại về năng suất do bệnh. Đối với mô hình nuôi quảng canh cải tiến, do mật độ nuôi thấp, chất thải từ tôm nuôi và việc cung cấp đầu vào không nhiều nên biến luân canh có mối tương quan không có ý nghĩa thống kê trong trường hợp này.

Tổng diện tích ao nuôi của nông hộ lớn thể hiện quy mô sản xuất của nông hộ. Quy mô sản xuất lớn giúp giảm thiệt hại về năng suất có thể do nông hộ sẽ có điều kiện đầu tư cho hệ thống ao nuôi tôm tốt hơn, chẳng hạn nông hộ có điều kiện dành một phần diện tích đất của mình để làm ao lắng, kênh dẫn nước tốt hơn. Trong mô hình nuôi bán thâm canh và thâm canh, ao lắng là cần thiết để giúp giảm mầm bệnh từ nguồn nước và ổn định môi trường nước trước khi đưa vào ao nuôi (Tran \& Nguyen, 2009) nên giúp giảm được thiệt hại về năng suất do bệnh. Tuy nhiên, kết quả khảo sát cho nhiều nông hộ nuôi tôm tại Sóc Trăng chưa quan tâm hoặc chưa có điều kiện đầu tư ao lắng. Có 49,7\% nông hộ sử dụng ao cho mô hình bán thâm canh và $52 \%$ cho mô hình nuôi tôm thâm canh.

Đặc điểm chung của 03 mô hình nuôi tôm sú là các yếu tố tham gia tổ hợp tác/hợp tác xã nuôi tôm sú, áp dụng kỹ thuật được tập huấn và sử dụng con giống xét nghiệm đều có ảnh hưởng có ý nghĩa thống kê đến tỷ lệ thiệt hại về năng suất tôm sú nuôi do bệnh. Khi tham gia tổ hợp tác/hợp tác xã nuôi tôm sú, nông hộ sẽ có điều kiện để trao đổi thông tin, kinh nghiệm nuôi tôm, liên kết trong sản xuất giúp giảm tỷ lệ thiệt hại về năng suất do bệnh. Sử dụng con giống được xét nghiệm giúp kiểm soát được mầm bệnh ban đầu, đồng thời đảm bảo được con giống có nguồn gốc và chất lượng tốt hơn nên giúp giảm được thiệt hại do bệnh. Tuy nhiên, kết quả khảo sát cho thấy vẫn còn nhiều nông hộ chưa thật sự quan tâm hoặc chưa có điều kiện để sử dụng con giống có xét nghiệm. Trong đợt khảo sát này, tỷ lệ hộ nuôi tôm sú sử dụng con giống được xét nghiệm là $43 \%, 48 \%$ và $53 \%$ lần lượt cho các mô hình quảng canh cải tiến, bán thâm canh và thâm canh. Điểm đáng chú ý là việc áp dụng các kỹ thuật được tập huấn vào trong quá trình nuôi đóng góp lớn nhất vào việc giảm tỷ lệ thiệt hại về năng suất. Tuy nhiên, tỷ lệ nông dân áp dụng các kỹ thuật được tập huấn vào quá trình nuôi tôm chiếm tỷ lệ rất thấp. Trong số 334 hộ được khảo sát, có 56,3\% hộ được tập huấn nhưng chỉ có 15,9\% hộ áp dụng.

\section{Kết Luận và Kiến Nghị}

\subsection{Kết luận}

Tỷ lệ thiệt hại về năng suất do bệnh hại trong mô hình nuôi hình nuôi tôm sú của nông hộ tại Sóc Trăng khá cao và mức độ thiệt hại tăng theo mức độ thâm canh.

Tham gia tổ hợp tác/hợp tác xã nuôi tôm sú, áp dụng kỹ thuật được tập huấn và sử dụng con giống được xét nghiệm giúp giảm thiệt hại về năng suất do bệnh trong nuôi tôm sú. Với mức độ thâm canh cao hơn (nuôi bán thâm canh hoặc thâm canh), trình độ học vấn của nông hộ, sử dụng ao lắng, luân canh với đối tượng khác và tăng diện tích đất sản xuất giúp giảm thiệt hại về năng suất do bệnh, trong khi độ tuổi càng cao thì nông hộ sẽ gặp nhiều thiệt hại về năng suất do bệnh. Trong đó, áp dụng kỹ thuật vào sản xuất có tác động giảm thiệt hại do bệnh hại tốt nhất.

\subsection{Kiến nghị}

Các ngành cần tiếp tục tăng cường tập huấn chuyển giao kỹ thuật nuôi tôm cho nông dân, chú ý nhiều hơn đến đối tượng nông hộ có trình độ học vấn thấp và độ tuổi cao.

Cần nghiên cứu yếu tố ảnh hưởng đến việc áp dụng kỹ thuật được chuyển giao của nông hộ nuôi tôm để làm cơ sở thúc đẩy việc áp dụng kỹ thuật vào nuôi tôm nhằm giảm thiệt hại do bệnh.

\section{Tài Liệu Tham Khảo (References)}

DF (Directorate of Fisheries). (2016). Soc Trang: maximizing the potential advantages in shrimp farming development. Retrieved February 1, 2018, from https://tongcucthuysan.gov.vn/soc-trang-phat-huytoi-da-tiem-nang-loi-the-trong-phat-trien-nuoi-tom.

Hoang, T., \& Chu, N. N. M. (2008). Analysis research data with SPSS. Ho Chi Minh city, Vietnam: Hong Duc Publishing House.

Le, H. V., Pham, K. C., Truong, M. H., \& Tran, H. N. (2012). Technical and financial efficiencies and linkages of different intensive shrimp (Penaeus monodon) farming models in Ben Tre and Soc Trang province. Can Tho University Journal of Science (24a), 78-87.

Le, M. T. P., Duong, N. V., \& Tran, H. N. (2014). Analysis on technical and financial aspects of shrimp $(\mathrm{Pe}$ - 
naeus monodon) intensice model in Soc Trang, Bac Lieu and Ca Mau provinces. Can Tho University Journal of Science (2), 114-122.

Nguyen, H. V., \& Nguyen, A. T. K. (2009). The factors affecting productivity of intensive black tiger shrimp farming - The case of Binh Dai district, Ben Tre provice, Vietnam. Journal of Fisheries Science and Technology (Special publications), 223-228.

Nguyen, L. T., Duong, H. V., \& Le, S. X. (2010). An analysis of technical and economic aspects of black tiger shrimp intensive culture in Soc Trang province. Can Tho University Journal of Science (14), 119-127.

Nguyen, L. T., \& Nguyen, P. T. (2010). Analysis of technical and economic aspects of coastal aquaculture systems in Soc Trang province. Can Tho University Journal of Science (14), 222-232.

PCSTP (People's Committee of Soc Trang Province). (2014). Decision on approving the fishery planning in Soc Trang province to 2020 and vision to 2030. No. 690/QDHC-CTUBND, July, 1, 2014.

Pham, T. L., \& Nguyen, P. T. (2015). Economic efficiency of intensive and semi-intensive shrimp production system in the Mekong River Delta. Journal of Economics and Development (217), 46-55.
SCAP [Enhancing gender equality in shrimp value chain in Soc Trang province project and Agricultural business investment in Vietnam and Southeast Asia project]. (2015). Report on Assessment of shrimp value chain in Soc Trang province. Retrieved from: Scap investigation and analysis.

STDARD (Soc Trang Department of Agriculture and Rural Development). (2016). Preliminary report on brackish water shrimp farming situation in 2016 and orientation for 2017. Soc Trang, Vietnam.

STDA (Soc Trang Department of Aquaculture). (2007). Report on examination and additional adjustment for planning on industrial shrimp farming areas by 2010 and orientations to 2020. Soc Trang, Vietnam.

Tran, H. N., \& Nguyen, P. T. (2009). Principles and techniques for raising black tiger shrimp. Ho Chi Minh City, Vietnam: Agricultural Publishing House. 